\title{
A Screening Experiment on a Diabetes Mellitus Herbal Formulation
}

\author{
Gladys Gakenia Njoroge ${ }^{1}$, Joseph Arap Koske ${ }^{2}$, Jemimah Ayuma Simbauni ${ }^{3}$ \\ ${ }^{1}$ Department of Physical Sciences, Chuka University, Chuka, Kenya \\ ${ }^{2}$ Department of Mathematics and Computer Science, Moi University, Eldoret, Kenya \\ ${ }^{3}$ Department of Zoological Sciences, Kenyatta University, Nairobi, Kenya
}

Email address:

gg.njoroge@gmail.com (G. G. Njoroge), koske4@yahoo.co.uk (J. A. Koske), jsimbauni@yahoo.com (J. A. Simbauni)

\section{To Cite this article:}

Gladys Gakenia Njoroge, Joseph Arap Koske, Jemimah Ayuma Simbauni. A Screening Experiment on a Diabetes Mellitus Herbal Formulation. American Journal of Theoretical and Applied Statistics. Vol. 5, No. 6, 2016, pp. 387-394. doi: 10.11648/j.ajtas.20160506.18

Received: October 15, 2016; Accepted: October 27, 2016; Published: November 18, 2016

\begin{abstract}
Screening experiments are usually performed on mixtures in order to determine the experimental variables that have significant influence on the targeted response. In this study, a screening experiment was carried out on a herbal formulation prescribed by a registered Kenyan herbalist to diabetes mellitus type II patients. The herbal formulation was composed of the following six herbs: Utica dioica, Moringaoleifera, Cinnamomum verum, Azadirachta indica, Momordica charantia and Gymnema sylvestre. The targeted response was the change that had occurred in blood glucose level 2 hours after the herbal drug treatment had been administered to alloxan induced diabetic albino wistar rats. An axial mixture design with replicated centre points was adopted and a first degree mixture model fitted to the data. The axial mixture design was constructed using Design Expert ${ }^{\circledR}$ software with randomly distributed 23 design points positioned on the component axes. The analysis of the data was carried out using the R statistical software environment. The results showed that Cinnamomum verum and Azadirachta indica caused the highest change individually on the blood glucose level among the six herbs. The complete mixture of the six herbs registered the lowest reduction in the blood glucose level. We recommend that the two herbs, Cinnamomum verum and Azadirachta indica, be tested farther to find out the most optimal conditions for their extraction in terms of temperature and time so as to produce a maximum reduction on the blood glucose level. In addition, we recommend that this study be extended to higher animals to establish whether the same patterns would be observed and also obtain the appropriate dosage levels.
\end{abstract}

Keywords: Screening Mixtures, Axial Design, Experiment, Herbal Medicine, Diabetes Mellitus

\section{Introduction}

Diabetes mellitus (DM) is defined by the American Diabetes Association [4] as "a group of metabolic diseases characterized by hyperglycemia resulting from defects in insulin secretion, insulin action or both." The chronic hyperglycemia of DM is associated with long-term damage, dysfunction and failure of different organs mainly the kidneys, the heart, eyes, nerves and the blood vessels, [4]. Diabetes mellitus is the fourth main contributor of global deaths among the non-communicable diseases (NCDs) according to World Health Organization [25]. It is estimated that about 415 million people have diabetes in the world and more than 14 million of this are in the African region. This figure is expected to be more than double by the year 2040 as predicted by International Diabetes Federation [12]. There were 478,000 cases of diabetes among the adults aged 20-79 years in Kenya in 2015 [12]. The prevalence rate was 3.3\% in 2008 and was predicted to rise to $4.5 \%$ by 2025 , [15]. The number of deaths among adults due to diabetes was estimated to be 8,722 , while the number of cases of diabetes in adults that were undiagnosed was 287,700. Meanwhile, the healthcare expenditure due to diabetes per person with diabetes in Kenya was $\$ 82.4$ in 2015, [12]. This high burden of diabetes mellitus in addition to the other noncommunicable diseases has hindered Kenya's progress towards achieving the Millennium Development Goals (MDGs) [26].Type 2 diabetes mellitus (T2DM) is the most common type of DM and can go unnoticed or undiagnosed 
for years. Over $90 \%$ of the diabetes patients are diagnosed with T2DM [17, 19 and 20]. In type 2 diabetes mellitus, either the body does not produce enough insulin or the cells in the body do not respond properly to the insulin (they are insulin resistant) or both.

Medicinal plants have played a key role in world health. There is a general shift in global trend from synthetic to natural medicine. Most rural populations especially in the developing countries depend on medicinal plants as their main source of primary health care [27]. Traditional healers and their herbal medicines provide the only health care to the majority of the people in curative rather than preventive approach in the developing countries for common ailments [1]. There has been an increasing acceptance and public interest in natural therapies in both developing and developed countries. Compared to conventional medicines, herbal drugs cost less, they are more readily available, are more often used to treat chronic diseases and the occurrence of undesirable side effects seem to be less frequent [5 and 14]. Over the years, the research on medicinal plants to elucidate the mechanism of action and to justify their claims by traditional healers has been on the increase [1 and 14]. Medicinal plants, especially in Africa and Asia have great potential to alleviate different array of ailments. However, these potentials are usually hampered by the ways and methods in which these plants are consumed, either directly as curative measures for ailments or as food supplements [16]. Based on their safety and their multiple targeting actions, herbal therapies are potent therapeutic means in T2DM [5].The use of diabetes mellitus herbal formulations is common as observed by [10]. These formulations are prepared by mixing a number of different herbs at given proportions. Such formulations for DM have different mode of action such as: increasing intestinal absorption of glucose, insulin-mimetic properties, stimulation of insulin secretion from the pancreatic beta cells, increased peripheral glucose uptake and inducing hypoglycaemic effect. Depending on the targeted mode of action for the diabetes mellitus herbal formulation, challenges exist on the lack of evaluation in terms of which of the mixed components contributes the most to the response.

Screening experiments are usually performed on mixtures in order to determine the experimental variables that have significant influence on the targeted response. When the number of potentially important components that can be considered as candidates in a mixture experiment is greater than or equal to six, it may become necessary to perform experimental runs to help decide the most important components [22]. The process of reducing the number of components so that only the components that have greatest effect on the response are considered for further tests is known as screening the components [7]. Screening is usually necessitated by the fact that it is easier to understand a system that contains reasonably smaller number of components. This is in addition to economic constraint involved in handling many components [6]. Screening experiment may be carried out to estimate a simple first order model with the primary goal being to identify the important factors [11]. Vine [23] defines screening as the process of sifting through a set of factors via experimentation to determine the few important factors that have a substantial effect on a response. Design-Expert ${ }^{\circledR}$ User's Guide [8] emphasizes the importance of screening as a first step in mixture experiments with many components. Snee and Markquardt [22] proposed simplex screening designs for qcomponents which contain: q-pure components, q-interior points (half-way between the vertices and the centroid) and q-end points (all permutations of $(0,1 /(q-1), \ldots 1 /(q-1)))$ giving $3 q+1$ or $2 q+1$ design points all together, when it is possible to experiment over the total composition range of all components $(0-100 \%)$. They recommended the fitting of a linear model for investigation where the relative effects are assessed by ranking the estimated coefficients $(\hat{\beta})$ of the standardised $x^{\prime} s$ in order by absolute value. Cornell [7] recommended the use of axial designs in screening experiments and when component effects are to be measured particularly when first degree models are to be fitted .The number of design points needed to fit the quadratic model in the case of six or more mixture components is quite large, especially considering that at the early stage of experimentation, one is not sure of the most effective components and/or the right component levels [7]. Cornell [6] acknowledges that construction of screening designs as well as the setting up of the appropriate screening models for mixture experiments quite often begins with the Scheffe first degree model. Weese [24] uses the Cox mixture models to develop a general method for screening a subset of components of mixtures with complex constraints. Goos and Bradley [11] noted that for the purpose of factor screening, many investigators use the main-effects model as the prior model with the assumption that higher-order effects, such as the two-factor effects, can be assumed. Kolthoff [13] recommended an axial mixture design with replicated centre points for screening experiments.

A herbal formulation consisting of six different herbs is prescribed by one of the herbalists in a Kenyan clinic to the diabetes patients for the purpose of inducing hypoglycaemic effect. The six herbal components are namely: Utica dioica (nettle), Moringa oleifera, Cinnamomum verum (cinnamon species), Azadirachta indica (neem), Momordica charantia (Bitter melon), Gymnema sylvestre. A screening experiment was set up to determine the herbal components in the formulation that were contributing the most to the reduction of the blood glucose level. The experiment was carried out using alloxan-induced diabetic albino wistar rats.

\section{Materials and Methods}

\subsection{The Experimental Animals}

The albino wistar rats were obtained from the Department of Zoological Sciences laboratory of Kenyatta University. The age of the rats selected for the study was 6-7 weeks old with $100-140 \mathrm{~g}$ body weight. A mixture of female and male albino wistar rats were housed in a room with a $12 \mathrm{~h}$ light and $12 \mathrm{~h}$ dark cycle at $25 \pm 3^{\circ} \mathrm{C}$. The animals were fed with standard rodent diet and water ad libitum. 
To induce diabetes mellitus, the rats were previously fasted for 16 hours and then given a single dose of intra-peritoneal injection of $150 \mathrm{mg} / \mathrm{kg}$ body weight, of $5 \%$ alloxan monohydrate dissolved in freshly prepared citrate buffer (0.1M, pH 4.5). The animals were tested for diabetes three days after induction. The blood sample used to check the blood sugar level was obtained by the tail clip method [2]. The testing procedure involved placing a drop of blood on a blood glucose test strip, GlucoPlus ${ }^{T M}$ and then inserting the strip into a clinical GlucoPlus ${ }^{T M}$ blood glucose meter. A Fasting Plasma Glucose (FPG) test was carried out after 12 hours of fasting. Fasting plasma glucose values $\geq 7.0 \mathrm{mmol} / \mathrm{l}$ $(126 \mathrm{mg} / \mathrm{dl})$ was considered as provisional diagnosis of diabetes. A 2-hour postload glucose $\geq 11.1 \mathrm{mmol} / \mathrm{l}$ $(200 \mathrm{mg} / \mathrm{dl})$ was used to confirm diabetes [3]. Measurements of the glucometer reading was in minimolar per litre $(\mathrm{mmol} / \mathrm{l})$, or $\mathrm{mg} / \mathrm{dl}$, where $1 \mathrm{mmol} / \mathrm{l}=18 \mathrm{mg} / \mathrm{dl}$.

\subsection{Preparation of the Herbal Drugs and the Dosage Calculation}

The volume of the dosage was done as per clinical trial guidelines, while taking into consideration the weight of the animal, the dose rate and the concentration of the crude herbal drug [18]. The corresponding equation was

$$
\text { Volumeofdose }(\mathrm{ml})=\frac{\text { doserate }(\mathrm{mg} / \mathrm{kg}) \times \text { bodyweight }(\mathrm{kg})}{\text { concentration }(\mathrm{mg} / \mathrm{ml})}
$$

The rat dose rate was calculated from the human dose rate assuming that: the human concentration is $4 \mathrm{gm} / 250 \mathrm{ml}$ and the average weight of human is $60 \mathrm{~kg}$. Using the equation (1), the human dose was obtained as

$$
\text { human dose } \begin{aligned}
\left(\frac{m g}{k g}\right) & =\frac{250 \mathrm{ml} \times \frac{0.016 \mathrm{gm}}{\mathrm{ml}}}{60 \mathrm{~kg}} \\
& =66.67 \mathrm{mg} / \mathrm{kg}
\end{aligned}
$$

The Animal Equivalent Dose (AED) was calculated using the formula

$$
A E D=\text { human dose }(\mathrm{mg} / \mathrm{kg}) \times \text { conversionfactor }
$$

The conversion factor is usually $37 / 6=6.167$ for rats [21].

Using the result in equation (2) and the formula in (3) the rat dose was obtained as $411.11 \mathrm{mg} / \mathrm{kg}$. This is the dosage value that the groups of rats receiving herbal drug treatment of the herbal drug extract received. To calculate the amount of herbal powder to be used per preparation, the formula (1) was employed as below:

$$
\begin{gathered}
\text { herbalconcentration }=\frac{411.11 \mathrm{mg} / \mathrm{kg} \times 0.16 \mathrm{~kg}}{1.5 \mathrm{ml}} \\
=43.85 \mathrm{mg} / \mathrm{ml}
\end{gathered}
$$

To prepare a $20 \mathrm{ml}$ volume of herbal drug solution, $877 \mathrm{mg}$ of the powdered herbal drug was used. The individual herbal drug extracts were collected from herbal suppliers and authentication was checked and confirmed. The proportion of each herbal drug in the mixture was dependent on the mixture design point. All the treatments were in aqueous form and were orally administered through Gavages' method.

\subsection{Design for the Screening Experiment}

An axial mixture design with replicated centre points was adopted as recommended by [12] and a first degree model fitted to the data as recommended by [6, 7 and 11]. The axial mixture design was constructed using Design Expert ${ }^{\circledR}$ software [8], with randomly distributed 23 design points positioned on the component axes.

\subsubsection{Treatment Arrangement for the Screening Experiment}

The albino wistar rats under study were first induced and confirmed to be diabetic as described in section (2.1.1). They were then randomly assigned into the following 23 groups of 4 animals ( 2 male and 2 female) each. The herbal mixture used as treatment was composed of the six components for each group as: Utica dioica $\left(x_{1}\right)$, Moringa oleifera $\left(x_{2}\right)$, Cinnamomum verum $\left(x_{3}\right)$, Azadirachta indica( $\left.x_{4}\right)$, Momordica charantia $\left(x_{5}\right)$, Gymnema sylvestre $\left(x_{6}\right)$. Each group received its treatment as a mixture whose component proportions was dependent on the axial design point and in the order $\left(x_{1}, x_{2}, x_{3}, x_{4}, x_{5}, x_{6}\right)$ as presented below.

Group 1: The rats in this group were treated with a herbal mixture consisting of all the six components in the proportion $(0.083333,0.583333,0.083333,0.083333,0.083333$, 0.083333 ), the main component being $x_{2}$.

Group 2:This group of rats were treated using a pure herbal mixture of $x_{5},(0,0,0,0,1,0)$.

Group 3: The rats in this group were treated with a herbal mixture consisting of all the six components in the proportion $(0.583333,0.083333,0.083333,0.083333,0.083333$, 0.083333 ), the main component being $x_{1}$.

Group 4: The rats in this group were treated using a pure herbal mixture of $x_{4},(0,0,0,1,0,0)$.

Group5: These rats treated with a herbal mixture consisting of all the six components at equal proportions $\left(\frac{1}{6}, \frac{1}{6}, \frac{1}{6}, \frac{1}{6}, \frac{1}{6}, \frac{1}{6}\right)$, the centroid of the design.

Group 6: This group of rats were treated with a herbal mixture consisting of all the six components in the proportion $(0.083333,0.083333,0.083333,0.583333,0.083333$, 0.083333 ), the main component being $x_{4}$.

Group 7: The rats in this group were treated using a pure herbal mixture of $x_{6},(0,0,0,0,0,1)$.

Group 8: These rats were treated with a herbal mixture consisting of all the six components at equal proportions $\left(\frac{1}{6}, \frac{1}{6}, \frac{1}{6}, \frac{1}{6}, \frac{1}{6}, \frac{1}{6}\right)$, a replicate of the centroid of the design.

Group 9: The rats in this group were treated with a herbal mixture consisting of all the six components in the proportion $(0.083333,0.083333,0.083333,0.083333,0.083333$, 0.583333 ), the main component being $x_{6}$.

Group 10: This group of rats was treated with a herbal mixture of proportions $\left(\frac{1}{5}, \frac{1}{5}, \frac{1}{5}, \frac{1}{5}, \frac{1}{5}, 0\right)$.

Group 11: Rats in this group were treated with a herbal 
mixture of proportions $\left(\frac{1}{5}, 0, \frac{1}{5}, \frac{1}{5}, \frac{1}{5}, \frac{1}{5}\right)$

Group 12: These rats were treated with a herbal mixture consisting of all the six components at equal proportions $\left(\frac{1}{6}, \frac{1}{6}, \frac{1}{6}, \frac{1}{6}, \frac{1}{6}, \frac{1}{6}\right)$, a replicate of the centroid of the design.

Group 13: These rats were treated with a herbal mixture consisting of all the six components at equal proportions $\left(\frac{1}{6}, \frac{1}{6}, \frac{1}{6}, \frac{1}{6}, \frac{1}{6}, \frac{1}{6}\right)$, a replicate of the centroid of the design.

Group 14: This group of rats was treated with a herbal mixture of proportions $\left(\frac{1}{5}, \frac{1}{5}, \frac{1}{5}, \frac{1}{5}, 0, \frac{1}{5}\right)$.

Group 15: The rats in this group were treated with a herbal mixture consisting of all the six components in the proportion $(0.083333, \quad 0.083333, \quad 0.583333,0.083333,0.083333$, 0.083333 ), the main component being $x_{3}$.

Group 16: Rats in this group were treated with a herbal mixture consisting of all the six components in the proportion $(0.083333, \quad 0.083333,0.083333,0.083333,0.583333$, 0.083333 ), the main component being $x_{5}$.

Group 17: This group of rats was treated with a herbal mixture of proportions $\left(\frac{1}{5}, \frac{1}{5}, \frac{1}{5}, 0, \frac{1}{5}, \frac{1}{5}\right)$.

Group 18: The rats in this group were treated with a herbal mixture of proportions $\left(\frac{1}{5}, \frac{1}{5}, 0, \frac{1}{5}, \frac{1}{5}, \frac{1}{5}\right)$.

Group 19: The rats in this group were treated using a pure herbal mixture of $x_{1},(1,0,0,0,0,0)$.

Group 20: This group of rats was treated with a herbal mixture of proportions $\left(0, \frac{1}{5}, \frac{1}{5}, \frac{1}{5}, \frac{1}{5}, \frac{1}{5}\right)$

Group 21: The rats in this group were treated using a pure herbal mixture of $x_{3},(0,0,1,0,0,0)$.

Group 22: The rats in this group were treated using a pure herbal mixture of $x_{2},(0,1,0,0,0,0)$.

Group 23: These rats were treated with a herbal mixture consisting of all the six components at equal proportions $\left(\frac{1}{6}, \frac{1}{6}, \frac{1}{6}, \frac{1}{6}, \frac{1}{6}, \frac{1}{6}\right)$, a replicate of the centroid of the design.

\subsubsection{Procedure for the Screening Experiment}

After confirmation of diabetes mellitus as described in section (2.1.1), the rats were then fasted over night but allowed to take water ad libitum. The fasting plasma glucose for each test rat was taken in the morning and recorded. The body weight of each test rat was also taken for the purpose of calculating the volume of treatment to be administered on each of the test rats. The next step was to administer glucose solution of $2 \mathrm{gm} / \mathrm{kg}$ body weight of the albino wistar rat dissolved in $1.4 \mathrm{ml}$ of water orally through Gavages' method to each test rat. The glucose solution was meant to raise the glucose level in the blood and the changes in the level of blood glucose thus monitored over time. The peak of the blood glucose level was estimated to occur 45 minutes after the glucose administration and therefore, BGL for each rat was taken at this time and recorded under $\mathrm{t}=45$. Immediately after taking the blood glucose level at $t=45$, the treatment was administered as a solution orally through Gavages' method to each test rat according to its weight. The next blood glucose level reading was taken at the $165^{\text {th }}$ minute of oral glucose consumption. The response measured was the change that had occurred in blood glucose level, 2 hours after the herbal drug treatment had been administered. This value was obtained from the difference between the blood glucose level reading at the $165^{\text {th }}$ minute and the $45^{\text {th }}$ minute from the time of oral glucose consumption.

\subsubsection{Analysis of Data from the Screening Experiment}

The analysis of the data was carried out using the $\mathrm{R}$ statistical software environment. To measure the effect of herbal mixture component $i$ on the response ( $y$ ), observations were taken at various points on the axis of component. The linear model (4) below was fitted into the experimental data.

$$
y(x)=\beta_{1} x_{1}+\beta_{2} x_{2}+\beta_{3} x_{3}+\cdots+\beta_{6} x_{6}+\varepsilon
$$

Where $\varepsilon$ represents the noise or error observed in the response $y, x_{i}$ represents the proportion of the $i^{\text {th }}$ component in the mixture and $\beta_{i}$ the model parameters.

The design matrix $(\mathrm{X})$ was obtained from the axial design and the moment matrix for the design was obtained as

$$
M=X^{\prime} X
$$

The estimated values of the coefficients $\beta$ of $x, \hat{\beta}$ i.e. $b_{1} b_{2} b_{3} b_{4} b_{5} b_{6}$, were obtained from the equation

$$
\hat{\beta}=\left(X^{\prime} X\right)^{-1} X^{\prime} y
$$

\subsubsection{Diagnostic Tests for the Fitted Model to the Screening Data}

The model was tested to check its fitness to the screening data.

\section{Test for Significance in Regression}

The first test was based on the assumption of normality of the error or residual term $\left(e_{i}\right)$. The test requires the $e_{i}$ 's to be normally and independently distributed with mean zero and variance $\sigma^{2}$. The residuals were obtained as the difference between the observed $\left(y_{i}\right)$ and the corresponding predicted value $\left(\hat{y}_{i}\right)$. The residuals were calculated from the formula

$$
e_{i}=y_{i}-\hat{y}_{i}
$$

And the studentised residuals obtained from the formula

$$
r_{i}=\frac{e_{i}}{S \sqrt{1-h_{i i}}}
$$

Where $h_{i i}$ are the elements of the hat matrix diagonals $\mathrm{H}=\mathrm{X}\left(\mathrm{X}^{\prime} \mathrm{X}\right)^{-1} \mathrm{X}$.

To facilitate the test on this assumption, a normal probability plot for the residuals was graphed. The normality assumption was satisfied if the residual plot was approximately along a straight line.

\section{Test for Significance of the Model}

If the normality condition was satisfied, it was then concluded that the $y_{i}$ 's were also normally and independently distributed. As a result, the test for the significance of regression could then be applied to see if a relationship existed between the response and the explanatory variables. The hypothesis was set as

$$
H_{0}: \beta_{1}=\beta_{2}=\beta_{3}=\beta_{4}=\beta_{5}=\beta_{6}=\text { constant } \text {, against }
$$

$$
H_{1}: \beta_{i} \neq \text { constant }
$$


The analysis of variance computations for the data using $\mathrm{R}$ were as follows:

First, the sums of squares;

$S S_{R}=b^{\prime} X y-\frac{\left(1^{\prime} y\right)^{2}}{n}$, for sum of squares for regression

$S S_{T}=y^{\prime} y-\frac{\left(1^{\prime} y\right)^{2}}{n}$, to obtain total sum of squares

$S S_{E}=S S_{T}-S S_{R}$, gave the residual sum of squares

Using the obtained sum of squares, an analysis of variance was carried out and the F-ratio obtained as in table 1 below, with $q$ model parameters and $\mathrm{n}$ experimental runs.

Table 1. ANOVA table for the screening experiment data.

\begin{tabular}{lllll}
\hline $\begin{array}{l}\text { Source of } \\
\text { variation }\end{array}$ & $\begin{array}{l}\text { Degrees of } \\
\text { freedom }\end{array}$ & $\begin{array}{l}\text { Sum of } \\
\text { squares }\end{array}$ & $\begin{array}{l}\text { Mean } \\
\text { squares }\end{array}$ & F-ratio \\
\hline Regression & $p-1$ & $\mathrm{SS}_{\mathrm{R}}$ & $\mathrm{MS}_{\mathrm{R}}$ & $\mathrm{MS}_{\mathrm{R}} / \mathrm{MS}_{\mathrm{Res}}$ \\
Residual & $n-p-1$ & $\mathrm{SS}_{\mathrm{Res}}$ & $\mathrm{MS}_{\mathrm{Res}}$ & \\
Total & $n-1$ & $\mathrm{SS}_{\mathrm{T}}$ & & \\
\hline
\end{tabular}

If the F-ratio was greater than the table F-value there was sufficient statistical evidence to reject the null hypothesis in favour of the alternative hypothesis. It was then concluded that at least one of the components was contributing significantly to the model and therefore, the model was adequate.

\section{Test for Significance of Parameter Estimates}

The test for significance of parameter estimates was undertaken to find out which of the six components was contributing significantly to the model (4). The hypothesis was set as

$$
H_{0}: \beta_{i}=0 \text { against } H_{1}: \beta_{i} \neq 0 \text {, where } i=1,2, \ldots, 6
$$

$\mathrm{T}$-statistics and their corresponding $\mathrm{p}$-values were obtained using $\mathrm{R}$ software environment. Components with $\mathrm{p}$-values less than 0.001 were considered to have a statistically significant effect on the response at $\alpha=0.001$ level of significance.

\subsubsection{Obtaining the Size of the Effect of Each Component on the Response}

To estimate the effect of component $i$ on the response $y$ in equation (4), equation (10) below was used at the base of the $x_{i}$-axis;

$$
\hat{y}(x)=\sum_{j \neq i}^{q} b_{j}(1 /(q-1))=(q-1)^{-1} \sum_{j \neq i}^{q} b_{j}
$$

Assuming data was collected only at the vertices of the simplex, then, $\hat{y}(x)$ in (10) is the average height of the response surface associated with the other $q-1$ pure components. At the vertex $x_{i}=1, x_{j}=0$, for all $j \neq i$, therefore, the estimate of the response becomes

$$
\hat{y}(x)=b_{i}
$$

Which was the estimated height of the surface at $x_{i}=1$. The effect of component $i$ on the response was defined as the change in the value of the response resulting from a change in the proportion of component $i$ while holding constant the relative proportions of the other components [7]. Therefore, the estimate of the effect of component $i$ on the response would be computed by comparing the $\hat{y}(x)$ values in (10) and (11). As a result, the effect of each component was obtained as

$$
\text { effect of component } i=b_{i}-(q-1)^{-1} \sum_{j \neq i}^{q} b_{j}
$$

Based on the results of section (2.3.4, part III) and the equation (12), the most important of the six components in terms of the effect in reducing the blood glucose levels of the diabetic albino wistar rats were obtained.

\begin{tabular}{|c|c|c|c|c|c|c|c|}
\hline \multicolumn{8}{|c|}{ Herbal drug components } \\
\hline$x_{1}$ & $x_{2}$ & $x_{3}$ & $x_{4}$ & $x_{5}$ & $x_{6}$ & Change in BGL2 hrs after treatment & Ave. change in BGL (y) \\
\hline 0.083333 & 0.583333 & 0.083333 & 0.083333 & 0.083333 & 0.083333 & $10.8,12.6,12,12.8$ & 11.8 \\
\hline 0 & 0 & 0 & 0 & 1 & 0 & $8.2,6.5,7.5,7.2$ & 7.35 \\
\hline 0.583333 & 0.083333 & 0.083333 & 0.083333 & 0.083333 & 0.083333 & $11.2,10.7,11.9,11.0$ & 11.2 \\
\hline 0 & 0 & 0 & 1 & 0 & 0 & $12.9,12.3,11.8,13.4$ & 12.6 \\
\hline 0.166667 & 0.166667 & 0.166667 & 0.166667 & 0.166667 & 0.166667 & $9.6,10.5,10.1,11.0$ & 10.3 \\
\hline 0.083333 & 0.083333 & 0.083333 & 0.583333 & 0.083333 & 0.083333 & $12.3,13,13.2,13.5$ & 13 \\
\hline 0 & 0 & 0 & 0 & 0 & 1 & $10.7,12.0,10.9,11.8$ & 11.35 \\
\hline 0.166667 & 0.166667 & 0.166667 & 0.166667 & 0.166667 & 0.166667 & $5.8,6.4,5.2,7.0$ & 6.1 \\
\hline 0.083333 & 0.083333 & 0.083333 & 0.083333 & 0.083333 & 0.583333 & $10.7,8.7,10.1,10.9$ & 10.1 \\
\hline 0.2 & 0.2 & 0.2 & 0.2 & 0.2 & 0 & $8.4,6.5,7.1,7.8$ & 7.45 \\
\hline 0.2 & 0 & 0.2 & 0.2 & 0.2 & 0.2 & $7.5,10.9,10.1,8.3$ & 9.2 \\
\hline 0.166667 & 0.166667 & 0.166667 & 0.166667 & 0.166667 & 0.166667 & $9.5,10.7,9.2,11.0$ & 10.1 \\
\hline 0.166667 & 0.166667 & 0.166667 & 0.166667 & 0.166667 & 0.166667 & $6.9,8.5,7.2,8.2$ & 7.7 \\
\hline 0.2 & 0.2 & 0.2 & 0.2 & 0 & 0.2 & $7.6,7.3,6.8,8.1$ & 7.45 \\
\hline 0.083333 & 0.083333 & 0.583333 & 0.083333 & 0.083333 & 0.083333 & $9.7,8.1,7.9,10.2$ & 8.9 \\
\hline 0.083333 & 0.083333 & 0.083333 & 0.083333 & 0.583333 & 0.083333 & $10.3,11.4,9.7,12.2$ & 10.9 \\
\hline 0.2 & 0.2 & 0.2 & 0 & 0.2 & 0.2 & $6.0,4.9,5.3,5.6$ & 5.45 \\
\hline 0.2 & 0.2 & 0 & 0.2 & 0.2 & 0.2 & $9.5,6.9,6.1,10.3$ & 8.2 \\
\hline 1 & 0 & 0 & 0 & 0 & 0 & $10.2,10.5,8.9,11.8$ & 10.35 \\
\hline 0 & 0.2 & 0.2 & 0.2 & 0.2 & 0.2 & $12.4,10.9,12.1,11.2$ & 11.65 \\
\hline 0 & 0 & 1 & 0 & 0 & 0 & $19.2,18.5,19.8,17.9$ & 18.85 \\
\hline 0 & 1 & 0 & 0 & 0 & 0 & $8.0,8.6,7.6,9.0$ & 8.3 \\
\hline 0.166667 & 0.166667 & 0.166667 & 0.166667 & 0.166667 & 0.166667 & $6.6,8.0,6.1,8.5$ & 7.3 \\
\hline
\end{tabular}

\section{Results and Discussion}

\subsection{The Results}

Table 2. Results of the Screening Experiment. 
Table 1 presents the changes in blood glucose level of each of the alloxan-induced diabetic albino wistar rat after taking the stated herbal blend and the corresponding average values of change in BGL for the two or three rats according the design point. From the results, the general observation was that, higher average change in BGL emanated from single components and complete mixtures with one component having a higher proportion. Further, lower average values of blood glucose level were observed in mixtures having equal proportions. For example, the average change in BGL of the five design points having equal proportions of six blends $\left(\frac{1}{6}, \frac{1}{6}, \frac{1}{6}, \frac{1}{6}, \frac{1}{6}, \frac{1}{6}\right)$ was 8.3 while pure components such as Cinnamon, Neem and Gymnema sylvestre caused higher changes individually. Similarly, for the equal proportions of the five components, the average of the six points is 8.23 which is much lower than the three single components. Cinnamon as a single component stood out as having the highest average change in the blood glucose level among all the other blends in this test. In a addition, the axial design used in this test displayed not just results for the single components in the design but also other complete mixtures in the interior of the design space that are useful in the screening analysis.

The estimated values of $\hat{\beta}$ i.e. $b_{1} b_{2} b_{3} b_{4} b_{5} b_{6}$ were obtained using the formula (6) and were presented in the table 3 below.

Table 3. Summary of the Analyzed Screening Experiment Results.

\begin{tabular}{llll}
\hline Component $(\boldsymbol{i})$ & Estimate $\left(\mathbf{b}_{\boldsymbol{i}}\right)$ & $\begin{array}{l}\text { Std. Error } \\
\text { value }\end{array}$ & $\operatorname{Pr}(>|\mathbf{t}|)$ \\
\hline $\mathrm{x}_{1}$ & 8.785 & 1.437 & $6.1151 .95 \mathrm{e}-07 * * *$ \\
$\mathrm{x}_{2}$ & 8.000 & 1.437 & $5.5691 .28 \mathrm{e}-06 * * *$ \\
$\mathrm{x}_{3}$ & 14.061 & 1.437 & $9.7878 .03 \mathrm{e}-13 * * *$ \\
$\mathrm{x}_{4}$ & 12.205 & 1.437 & $8.4965 .55 \mathrm{e}-11 * * *$ \\
$\mathrm{x}_{5}$ & 7.117 & 1.437 & $4.9541 .03 \mathrm{e}-05 * * *$ \\
$\mathrm{x}_{6}$ & 9.520 & 1.437 & $6.6273 .31 \mathrm{e}-08 * * *$ \\
\hline
\end{tabular}

Significant codes: ‘ $* * *$ ’ at $\alpha=0.001$

Table 3 showed that the effect on the change in blood glucose level for each of the six components was significant at $\alpha=$ 0.001 level of significance, but was most significant for components $\mathrm{x}_{3}, \mathrm{x}_{4}$ and $\mathrm{x}_{6}$. The values of $b_{1} b_{2} b_{3} b_{4} b_{5} b_{6}$ were therefore:

$b_{1}=8.785, b_{2}=8.000, b_{3}=14.061, b_{4}=12.205$, $b_{5}=7.117, b_{6}=9.52$

The resulting fitted linear model for the six components was thus:

$$
\hat{y}(x)=8.78 x_{1}+8 x_{2}+14.06 x_{3}+12.21 x_{4}+7.12 x_{5}+9.52 x_{6}
$$

\subsection{Diagnostic Tests for the Fitted Model to the Screening Experiment Data}

The linear model was tested to check its fitness to the screening experiment data.

\subsubsection{Test for Significance in Regression}

This first test was based on the assumption of normality of the error terms $\left(e_{i}\right)$ as outlined in section $(2.3 .4$, part I). To facilitate the test of this assumption, a normal probability plot for their residuals was graphed as in fig. 1 below.

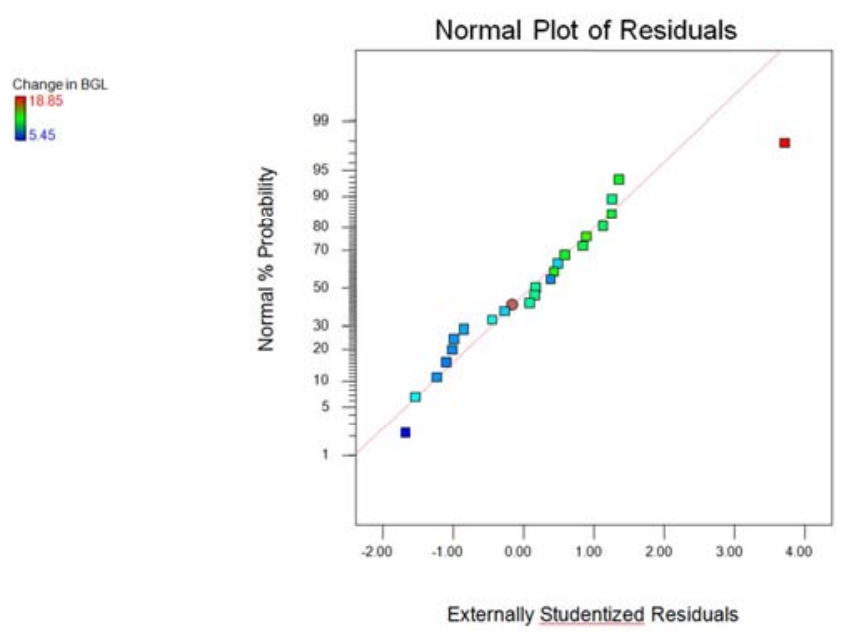

Figure 1. Normal Probability Plot of the Residuals for the Screening Experiment Data.

From fig. 1, it was observed that the points lay approximately on the straight line and hence the normality condition was satisfied. Given that the normality condition was satisfied, it was then concluded that the $y_{i}$ 's were also normally and independently distributed. As a result, the test for the significance of regression could then be applied to see if a relationship existed between the response and the explanatory variables.

\subsubsection{Test for the Significance of the Model}

The hypothesis was set as in section (2.3.4., part II). The analysis of variance computations for this data using $\mathrm{R}$ were as follows:

First, the sums of squares;

$$
\begin{gathered}
S S_{R}=b^{\prime} X y-\frac{\left(1^{\prime} y\right)^{2}}{N}=100.05 \\
S S_{T}=y^{\prime} y-\frac{\left(1^{\prime} y\right)^{2}}{N}=402.69 \\
S S_{E}=S S_{T}-S S_{R}=302.64
\end{gathered}
$$

Table 4. ANOVA Results for the screening experiment data.

\begin{tabular}{lllll}
\hline $\begin{array}{l}\text { Source of } \\
\text { variation }\end{array}$ & $\begin{array}{l}\text { Degrees of } \\
\text { freedom }\end{array}$ & $\begin{array}{l}\text { Sum of } \\
\text { squares }\end{array}$ & $\begin{array}{l}\text { Mean } \\
\text { squares }\end{array}$ & F-ratio \\
\hline Regression & 5 & 100.05 & 20.01 & 3.04 \\
Residual & 46 & 302.64 & 6.579 & \\
Total & 51 & 402.69 & & \\
\hline
\end{tabular}

Since F-ratio $=3.04>\mathrm{F}_{(5,46,0.05)}=2.45$, there was sufficient statistical evidence to reject the null hypothesis in favour of the alternative hypothesis. It was concluded that at least one of the components was contributing significantly to the model and therefore, the model was adequate.

\subsubsection{Test for Significance of Parameter Estimates}

The next step involved carrying hypothesis test to find out 
which of the components was contributing significantly to the model. The hypothesis was set as presented in section (2.3.4, part III)

From the results of table 3 , there was significant evidence to reject the null hypothesis and conclude that all the parameters were significant at $\alpha=0.001$ level and were all required in explaining the change in the blood glucose level. Notably from these results, cinnamon and neem had the most statistically significant results.

\subsection{Testing the Effect of the Components}

Using formula (7), the effect of each of the six components was calculated and results summarized in the table 5 below: For example, effect of component $1=8.785-$ $\frac{8+14.06+12.21+7.12+9.52}{5}=-1.397$

Table 5. A Summary of the Effect on BGL of Each of the Six Components.

\begin{tabular}{ll}
\hline Component $(\boldsymbol{i})$ & Effect of Component $(\boldsymbol{i})$ on BGL \\
\hline Nettle $\left(\mathrm{x}_{1}\right)$ & -1.397 \\
Moringa $\left(\mathrm{x}_{2}\right)$ & -2.158 \\
Cinnamon $\left(\mathrm{x}_{3}\right)$ & 5.114 \\
Neem $\left(\mathrm{x}_{4}\right)$ & 2.882 \\
Karela $\left(\mathrm{x}_{5}\right)$ & -3.226 \\
Gymnema $\left(\mathrm{x}_{6}\right)$ & -0.514 \\
\hline
\end{tabular}

From the results in table 5, the positive values of the effect of the components imply that the component produced a greater effect on the change in blood glucose level than the average of the remaining five components. The Components $\mathrm{x}_{3}$ (Cinnamon) and $\mathrm{x}_{4}$ (neem) had positive values on the effect of the component and therefore produced a greater effect on the change in the blood glucose level than the average of the other five components in each case.

\section{Summary, Conclusions and Recommendations}

\subsection{Summary of the Findings}

The results in section (3.1) showed that greater changes in BGL resulted generally from pure mixtures and those complete mixtures with at least one component having a high proportion than the rest five. The complete mixtures with equal proportions had relatively smaller changes implying that the size of change in BGL is determined not just by the components present in the mixture but also their proportions. The linear model was found to be a good fit to the data and all the six herbal drug components contributed to the reduction in the blood glucose level to some extent. However, the largest reductions were by $x_{3}$ (cinnamon) followed by $x_{4}$ (neem). The test on the effect of each component in section (3.3) confirmed that the effect of cinnamon and neem was high above that of the average of the other five. The two components were therefore the most effective in controlling the blood glucose level with cinnamon taking the lead.

\subsection{Conclusions and Recommendations}

The findings of this study have shown that first mixing of different herbs does not necessarily improve the response, reduction of blood glucose level, for the diabetic rats which could be as a result of antagonistic interaction effect among the herbs. Secondly, the most effective single herbs for reducing the blood glucose level among the six that were involved in this study were the cinnamon and neem. The reduction that each of the two herbs produced on the blood glucose level far much exceeded that of the complete mixture of the six herbs and the remaining four herbs. We therefore recommend that these two herbs, cinnamon and neem be tested farther to find out the most optimal conditions for their extraction in terms of temperature and time so as to produce a maximum reduction on the blood glucose level. In addition, we recommend that this study be extended to higher animals to establish whether the same patterns would be observed and also obtain the appropriate dosage levels.

\section{References}

[1] Agbor, G. A., Kuate, D. and Oben, J. E., "Medicinal plants can be good source of antioxidants: Case study in Cameroon," Pakistan Journal of Biological Sciences, 10 (4), 537-544, 2007.

[2] Alarcon-Aguilar, F. J., Jimenez-Estrada, M., Reyes-Chilpa, R., Gonzalez-Paredes, B., Contheras- Weber, C. and RomanRamos, R., "Hypoglycemic activity of root water decoction, sesquierpenoids and one polysaccharide fraction from Psacaliumdecompositum, in mice," Journal of Ethnopharmacology, 69, 207-15, 2000.

[3] American Diabetes Association, ADA, "Standards of medical care in diabetes-2016," Diabetes Care, 39 (suppl 1), S1- S106, 2016.

[4] American Diabetes Association, "Diagnosis and classification of diabetes mellitus," Diabetes Care, 34 (suppl 1), S62- S69, 2011.

[5] Chang, C. L. T., Lin, Y., Bartolome, A. P., Yi-Ching, C., Shao-Chih, C. \& Wen-Chin, Y., "Herbal therapies for type 2 diabetes mellitus: Chemistry, Biology and potential application of selected plants and compounds," Evidencebased Complementary and Alternative Medicine-33Article ID 378657.http://dxdoi.org /10.1155/2013/378657, 2013.

[6] Cornell, J. A., Experiments with Mixtures: designs, models and the analysis of mixture data, $3{ }^{\text {rd }}$ Edition,New York: John Wiley \& Sons, Inc,2002.

[7] Cornell, J. A., Experiments with Mixtures: Designs, Models and the Analysis of Mixture Data, $2^{\text {nd }}$ Edition,New York: John Wiley \& Sons, Inc, 1990.

[8] Design-Expert ${ }^{\circledR}$ User's Guide, Split-plot Tutorial, Stat-Ease, Inc. Minneapolis, 2016.

[9] Design-Expert ${ }^{\circledR}$ Software Version 10, State-Ease Inc, Minneapolis, 2016. 
[10] Dwivedi, C., Daspaul, S., "Antidiabetic herbal drug and polyherbal formulation used for diabetes: a review," Journal of Phytopharmacology,2(3), 44-51, 2013.

[11] Goos, P. and Bradley, J., Optimal Design of Experiments: A Case Study Approach, New York: John Wiley \& Sons, Inc, 2011.

[12] International Diabetes Federation, IDF Diabetes Atlas, $7^{\text {th }}$ Edition, 2015.

[13] Kolthoff, I. M., Getting started with v10 of Design-Expert Software, Stat- Ease, Inc. Minneapolis, 2016.

[14] Matheka, D. M. and Alkizim, F. O., "Complementary and alternative medicine for type 2 Diabetes Mellitus: Role of medicinal herbs," Journal of Diabetes and Endocrinology, 3(4), 44-56, 2012.

[15] Mcferran, L., "Obstacles to diabetes care in Kenya,"Medical Journal of Therapeutics Africa, 2(2), 127-129, 2008.

[16] Odey, M. O., Iwara, I. A., Ubiba, U. U., Johnson, J. T., Inekwe, U. V., Asenye, M. E. and Victor, O.,"Preparation of Plant Extracts from indigenous medicinal plants,"International Journal Science and Technology, 1 (12), 688-692, 2012.

[17] Ozougwu, J. C., Obimba, K. C., Belonwu, C. D. and Unakalamba, C. B., "The pathogenesis and phathophysiology of type 1 and type 2 diabetes mellitus," Journal of Physiology and Pathophysiology, 4(4), 46-57, 2013.

[18] Reagan, S. S., Nihal, M. and Ahmad, N.,"Dose translation from animal to human studies revisited,"The FASEB Journal, 22(3), 659-661, 2007.
[19] Sangal, A.,"Role of Cinnamon as beneficial ant diabetic food Adjunct: a review," Advances in Applied Sciences Research, 2(4), 440-450, 2011.

[20] Shaw, J. E., Sicree, R. A. andZimmet, P.Z.,"Global estimates of the prevalence of Diabetes for 2010 and 2030,"Diabetes Research and Clinical Practice, 87(1), 4-14, 2010.

[21] Shin, J-W., Seol, I-C. and Son, C-G., "Interpretation of animal dose and human equivalent dose for drug development,"The Journal of Korean Oriental Medicine, 31(3), 1-7, 2010.

[22] Snee, R. D. and Marquardt, D. W.,"Screening concepts and designs for experiments with mixtures,"Technometrics, 18(1), 19-29, 1976.

[23] Vine, A. E.,"Two-stage group screening”, $\mathrm{PhD}$ thesis, school of Mathematics, Faculty of Engineering Science and Mathematics; University of Southampton, 2004.

[24] Weese, M.,"A new screening methodology for mixture experiments", PhD diss., University of Tennessee, Knoxville, 2010.

[25] World Health Organization, Global report on diabetes, Geneva, Switzerland, 2016.

[26] World Health Organization, Kenya country cooperation strategy at a glance, Geneva, Switzerland,2014http://www.who.int/countryfocus/cooperatio n_strategy/ccsbrief_ken_en.pdf.

[27] World Health Organization, WHO traditional medicine strategy 2014-2023, Geneva, Switzerland, 2013. 